\title{
Innovations in postgraduate work integrated learning within the perioperative nursing environment: A mixed method review
}

Follow this and additional works at: https://www.journal.acorn.org.au/jpn

Part of the Health Services Research Commons, Perioperative, Operating Room and Surgical Nursing Commons, and the Surgery Commons

(c) (1)

This work is licensed under a Creative Commons Attribution 4.0 License.

\section{Recommended Citation}

Russell, Kylie P. and Coventry, Tracey Dr (2019) "Innovations in postgraduate work integrated learning within the perioperative nursing environment: A mixed method review," Journal of Perioperative Nursing: Vol. 32 : Iss. 1 , Article 5.

Available at: https://doi.org/10.26550/2209-1092.1041

https://www.journal.acorn.org.au/jpn/vol32/iss1/5

This Article is brought to you for free and open access by Journal of Perioperative Nursing. It has been accepted for inclusion in Journal of Perioperative Nursing by an authorized editor of Journal of Perioperative Nursing. 


\section{Innovations in postgraduate work integrated learning within the perioperative nursing environment: A mixed method review}

\section{Cover Page Footnote}

The authors would like to acknowledge the Fremantle Hospital and Health Service nursing management, education department and executive whose vision and leadership supported the introduction of the perioperative course and its accreditation with The University of xxx. Ongoing success of the program would not have been possible without each participating health service, who continue to provide specialist staff and employment for students. The dedication of the perioperative nurse educators and mentors has been integral to the success of the program and its students. 


\section{Authors}

Kylie P Russell

PhD, MHSc(Ed), GCHRM, BN, RN

Associate Professor, School of Nursing

and Midwifery, University of Notre Dame,

Australia

Tracey Coventry

PhD, MNursEd, RN, RM

Postgraduate Coordinator and senior

lecturer, University of Notre Dame,

Australia

\section{Corresponding author}

Kylie P Russell

PhD, MHSc(Ed), GCHRM, BN, RN

Associate Professor, School of Nursing

and Midwifery, University of Notre Dame,

Australia

kylie.russell@nd.edu.au

\title{
Innovations in postgraduate work integrated learning within the perioperative nursing environment: A mixed method review
}

\begin{abstract}
Purpose: To determine the impact of the Graduate Diploma of Perioperative Nursing on student learning and career progression.

Participants and setting: A validated mixed methods descriptive survey was sent to participants ( $n=67)$. Findings were analysed using descriptive statistics and results were further investigated using a focus groups of 12 individuals.

Methods: Overall 96 per cent of graduates were satisfied with the program and agreed that the program had improved their delivery of patient care and enhanced their application of theoretical knowledge to clinical skills. Three themes were identified from data from the focus groups: 'learning', 'empowerment' and 'opportunity'. Qualitative findings confirmed program satisfaction among participants who valued the learning experience.
\end{abstract}

Conclusion: The Graduate Diploma of Perioperative Nursing provides a unique opportunity for nurses in Western Australia to engage in a workplacesupported program to consolidate their specialised practice. With significant cutbacks occurring in nursing education across both the private and public health care sectors, the profession should advocate for the role of work integrated learning as a strategy to support nurses' development in a complex and changing health workplace.

\section{Introduction}

Within nursing academia and the health services there is ongoing discussion and concern about the practice-to-theory gap in undergraduate ${ }^{1}$ and postgraduate speciality practice programs. Postgraduate programs providing specialist clinical practice cannot validate clinical and professional competence in their learning outcomes without student engagement in the clinical environment. However, providing workplace learning opportunities for postgraduate programs remains limited ${ }^{2}$. Entry to practice registered nurse placements are limited and remain the priority for universities and the profession, therefore reducing potential supernumerary clinical placements for postgraduate students.

The Graduate Diploma of Perioperative Nursing delivered at an Australian university aims to meet the needs of both theory and clinical practice with an understanding that supernumerary positions are limited. The program, rather than requiring clinical placement, instead uses a model of work integrated learning, as previously reported ${ }^{3}$. With increased pressure on health services to practice with efficient staffing levels and reduced access to staff learning and development, senior nurses advocating for the program have requested further data to support the impact of the 
program on participants. This data will assist when budget requests are made concerning student numbers, access to program resources such as support to attend face-to-face staff development programs, rotation through a variety of theatres

(which impacts on orientation and supernumerary time) and availability of senior staff to provide assessment and feedback concerning new nurses' practice.

\section{Study design}

The research aim was to determine the impact of the Graduate Diploma of Perioperative Nursing on student learning and career progression. A concurrent mixed method design as described by Creswell ${ }^{4}$ was used for this study. This involved the collection and analysis of qualitative and quantitative data separately.

A validated mixed method descriptive work integrated learning (WIL) survey was sent to graduates from the previous five years $(n=67)$. Potential participants were encouraged to forward the information to colleagues as some of the contact information held by the university may not have been current (referred to as a Snowballing technique ${ }^{5}$ ). Data analysis for the survey data involved the use of descriptive statistics.

To provide further depth to the survey findings, graduates of the 2017 program $(n=12)$ participated in a focus group ( $n=11)$. The focus group technique was used as a strategy to validate and explain the survey themes identified. Focus groups provided an opportunity for participants to share their stories, opinions and thoughts about the given topic 6 .

\section{Findings}

Of the potential 67 participants meeting the inclusion criteria for phase one of the study, the online

Table 1: Response rate WIL survey by year $(n=21)$

\begin{tabular}{|c|c|c|c|c|c|}
\hline & 2013 & 2014 & 2015 & 2016 & 2017 \\
\hline Number & 4 & 4 & 4 & 4 & 5 \\
\hline
\end{tabular}

survey, a response rate of 22 (33 per cent) was obtained. Table 1 shows the number of respondents from each of the five years from 2013 to 2017 (one respondent did not identify which year they studied.)

Of the 33 per cent of participants that replied, 86 per cent had already been working in the perioperative suite prior to program commencement, 9 per cent had a student clinical placement as their only experience, and 5 per cent had no previous experience.

Demographic details highlighted a range of ages of the participants, as outlined in Table 2.

Table 2: Age of participants

\begin{tabular}{|c|c|}
\hline Age & Number \\
\hline $21-25$ & 3 \\
\hline $26-30$ & 5 \\
\hline $31-35$ & 4 \\
\hline $36-40$ & 4 \\
\hline $41-45$ & 4 \\
\hline $46-50$ & 2 \\
\hline
\end{tabular}

\section{Quantitative findings}

The adapted WIL survey indicated that 39 per cent of the participants had gained a promotion since completing the program with a further 55 per cent of the remaining 61 per cent having had the opportunity to act in senior positions.

Responses to questions relating to the program were rated on a five-point Likert scale, with the five points equivalent to 'very satisfied', 'somewhat satisfied', 'neutral', 'not very satisfied' and 'not at all satisfied'.

A high percentage of participants were satisfied with the program with 96 per cent articulating they were either very satisfied or somewhat satisfied. Particular aspects of the program and the percentage of participants who responded that they were satisfied are as follows:

- the study days (100 per cent)

- staff development support (90 per cent)

- online academic content (96 per cent)

- WIL (96 per cent).

The impact of the program on participant's knowledge, skills and abilities was measured with a fivepoint Likert scale of 'strongly agree', 'agree', 'neither agree nor disagree', 'disagree' and 'strongly disagree'. The data indicated that participants:

- agreed that the program had improved their delivery of patient care (96 per cent)

- agreed that the program had improved their application of theoretical knowledge to clinical skills (96 per cent).

Additionally, participants agreed that the following aspects were improved by the program (percentage of participants shown in brackets):

- perioperative practice (100 per cent)

- critical thinking (81 per cent)

- reflective practice (84 per cent)

- evidence-based practice (100 per cent)

- independent learning (96 per cent) 
Nearly all participants (96 per cent) agreed that academic support provided by the university had impact on their knowledge, skills and abilities and 55 per cent stated that they were interested in further study.

\section{Qualitative findings}

The qualitative findings supported the quantitative data that overall participants enjoyed the program and felt that it provided a unique opportunity to learn and consolidate the knowledge, skills and attitudes for perioperative nursing. Three themes were identified from the data, 'learning', 'empowerment' and 'opportunity'.

\section{Learning}

In the online survey and in the focus groups participants made openended comments that the online platform and study days provided a positive place to engage in learning. The study days in particular brought together all of the students from across the various health care sites. This allowed opportunities to share experiences, stories and ways of practicing.

Participants felt that there were varied learning opportunities provided in the program. These different sources of information supported understanding and the ability to apply information to different scenarios. Statements of support by the participants included:

'Study days and hands on practice with equipment'.

'Rotating through specialities has given me the skills and ability to operate in all fields.'

This application of learning was supported through the assessment tasks. Assessments promoted learning through the application of perioperative practice, as highlighted by participant comments:
'Case study assignment good in outlining pre-, intra-, and postoperative care required for optimal patient care in perioperative setting.'

'I've actually read more policies and standards in this year than I did in my previous working... so I think it makes you actually go and look things up and see what it actually says.'

As a result of these learning opportunities, participants described how they had increased their knowledge and skills for perioperative nursing practice and how this directly related to improved consideration of practice:
'Ability to learn new skills/
information that has helped me to advance'.
'My learning helped me to be
less task-orientated and more evidence-based in my nursing and I feel that it has enabled me to be a better periop nurse and has refocused my purpose on the patient's wellbeing'.
'You're always thinking about all the little things that you're doing that maybe you didn't think of before'.

There were some comments related to the academic requirements of completing a graduate diploma and learning the skills of referencing and academic writing. However, despite these extra requirements, participants appreciated that the national standards of education must be met for the qualification of a graduate diploma. One program change that participants felt impacted significantly on student learning was the removal of inter-hospital placements. Until 2013 students were required to undertake a rotation outside of their health service; in particular, students crossed between public and private health services and tertiary and secondary centres. Due to the introduction of centralised staff systems, hospitals in the public system found this process increasingly challenging resulting in its cessation. Participants felt strongly about the placement removal, and believed that it should be brought back into the program.

'I think the course should be reverted back to allow students to be rotated around each host hospital, I found that beneficial in gaining more experience through spending time in different hospitals' specialty areas'.

\section{Empowerment}

The extension of knowledge and skills empowered students to question practice and seek new ways of providing care. There was a consensus that practice in many cases is routine:

'I also find people do stuff in theatre that they've done for years, that's just because they do it that way.'

At times students found it frustrating when staff could offer no evidencebased practice reason for their teaching and direction of care:

'There's no backing behind what they do.'

The knowledge gained from the program and the requirement to review national and international best practice standards and publications provided students with a greater sense of confidence to question practice and make recommendations for practice.

'You've got confidence, and you understand the process behind why things come about... you can speak up about things, because you know that you've read about it.' 


\section{Opportunity}

Completion of the program was seen to provide an advantage when applying for promotional positions or being allocated increased responsibility within the health service. Participants in the surveys outlined promotions within their unit, opportunities to act in senior roles, and being asked to join committees and take on extra responsibilities.

'I think looking at other people who have done the course over the past few years ... who are now acting CNs, or even if they're not acting CNs, they've taken on responsibilities, or are facilitators for the students that come through, so it's kind of... either they're more driven, which led them to do the course, but has also led them to get promotions, or whether the course helped them in the interviews to get those positions. I think... there is a connection between taking on more duties and having done it.'

Further to this opportunity was the networking that occurred across health services and across year groups. An informal alumni had developed:

'I think a lot of the people that have done the course previously are quite proud of it as well, and that I found a lot of people that had done it, they'd go, 'Oh, how are you going?... How are you finding this?' and they're willing to give their support.'

\section{Discussion}

Work integrated learning (WIL) describes the collaboration between higher education institutions and industry to provide workplace learning. Workplace learning supports the application of theory to practice which develops the essential skills, experience and an understanding of the 'real' world of the chosen profession",

Findings of this study suggest that the Graduate Diploma of Perioperative Nursing provides a unique opportunity to support perioperative nurses in their professional practice. The results from the research data have indicated that participants found the program to be of benefit to their professional knowledge and practice and that career promotions and opportunities had been linked to the program.

Despite these benefits, the application of WIL in postgraduate nursing education remains relatively untapped ${ }^{7,8}$. Cutbacks in learning and development departments and reduced access to professional development time have significantly hindered their introduction and continuation. In particular, postgraduate levels of education in nursing in Australia are at risk of falling behind comparable nations. A recent report conducted by the Victorian Government Department of Health ${ }^{9}$ clearly cited postgraduate education as a priority to nurses and that the greatest barrier was cost. The paper suggested removing postgraduate education from the academic setting and aligning it with professional colleges as is the case for postgraduate specialty medical education. Such colleges work in a similar arrangement to the perioperative course, aligning education within the hospital system and so reducing costs. This model, which is also used by the perioperative program under the banner of WIL, can provide an alternative solution that continues to engage with the university sector.

\section{Limitations}

There may have been a number of potential participants who did not receive their invitation to partake in the study due to changes in the contact details of some students since enrolment and despite the researchers encouraging participants to share the recruitment email with other program participants that they knew. This study relates only to the work integrated program the Graduate Diploma of Perioperative Nursing provided through an Australian university. The findings of this study do not translate to other WIL programs provided by the university or other universities.

\section{Recommendations}

The study findings have provided evidence to support the perceived benefits of the Graduate Diploma of Perioperative Nursing, and in particular WIL. The use of the WIL model of education in postgraduate nursing education should be considered further by schools of nursing to support the ongoing learning needs of registered nurses. specialised nursing clinical practice cannot be taught and learnt from the classroom without the opportunity to apply theory to practice. Departments of health should be encouraged to work with the education sector to consider further opportunities for postgraduate WIL to meet the demanding needs of the profession.

\section{Conclusion}

The Graduate Diploma of Perioperative Nursing provides a unique opportunity for nurses in Australia to engage in a workplace supported program to consolidate their specialised practice. With significant cutbacks in nursing education across both the private and public health care sectors, the profession should advocate for the role of WIL as a strategy to support 
nurse's development in a complex and changing health workplace. Nurses can ill afford to ignore their responsibility to lifelong learning and professional development in the rapidly advancing health industry. However, increasing costs associated with academic education remains a significant barrier to engagement in further education.

The findings of this study suggest that the participants engaged with the program content and delivery and had been able to apply their learning to practice. Of the 22 participants that participated in the WIL survey all indicated that they planned to stay in nursing with only one unsure about their future in perioperative nursing. Further to this, participants agreed that the program was of benefit to their professional practice and offered opportunities for learning and promotion; however, all agreed that the program needed to incorporate rotations across health service sites as previously included.

\section{References}

1. Ralph N, Birks M, Cross W, Chapman Y. 'Settling for less': Designing undergraduate nursing curricula in the context of national accreditation. Collegian 2017;24(2):117-124.

2. Department of Health. Nursing and midwifery education [Internet]. Canberra: Department of Health; 2013.

3. Russell K, Coventry T. Innovations in postgraduate work integrated learning within the perioperative nursing environment: A Western Australian experience. Journal of Perioperative Nursing 2017;29(4): 15-19.
4. Creswell J. Research design: Qualitative, quantitative, and mixed methods approaches. $4^{\text {th }}$ ed. Los Angeles: Sage, 2014

5. Schneider Z, Whitehead D, LoBiondo-Wood $G$, Haber J. Nursing and midwifery research: Methods and appraisal for evidence-based practice. $5^{\text {th }}$ ed. Chatswood: Elsevier, 2016.

6. Polit D, Beck C. Essentials of nursing research: Appraising evidence for nursing practice. $9^{\text {th }}$ ed. Philadelphia, PA: Wolters Kluwer, 2018.

7. Drysdale M, McBeath M, Johansson K, Dressler S, Zaitseva E. Psychological attributes and work-integrated learning: An international study. Higher education, skills and work-based learning 2016;6(1):20-34.

8. Johnston M, Bishop R. Noongar Dandjoo: A work-integrated learning case study. Asia Pacific Media Educator 2012;22(2):165-77.

9. Darcy associates. Review of postgraduate nursing and midwifery education in Victoria. St Kilda, Vic: Darcy Associates; 2015. 